\title{
Biochemical and Genetic Characteristics of Deletion and other Mutant Strains of Salmonella typhimurium LT2 Lacking $\alpha$-Keto Acid Dehydrogenase Complex Activities
}

\author{
By D. LANGLEY AND J. R. GUEST \\ Department of Microbiology, University of Sheffield, Sheffield Sro $2 T N$
}

(Received 9 January 1974)

\begin{abstract}
SUMMARY
Mutants of Salmonella typhimurium LT2 requiring acetate or succinate for aerobic growth on glucose were isolated. One acetate-requiring mutant, s8, lacked the activity of the overall pyruvate dehydrogenase complex due to a deficiency in the pyruvate dehydrogenase component (EIp) and was therefore designated an ace $E$ mutant. Another mutant, s6, which required succinate (or lysine plus methionine), lacked activities of the overall $\alpha$-ketoglutarate dehydrogenase complex and the $\alpha$-ketoglutarate dehydrogenase component (EI kg) and was designated a sucA mutant. Genetic studies with these mutants established that like Escherichia coli KI2, Salmonella typhimurium LT2 has an aceE gene linked to aziA and aroP thus: leu-aziA-aroP-aceE, and a sucA gene linked to nadA thus: sucA-nadA-gal.

Two deletion strains, SMI6 and SM5I, which required acetate, or better, acetate plus lysine plus methionine, were found to lack the overall activities of both $\alpha$-keto acid dehydrogenase complexes. Biochemical and immunological studies showed this to be due to deficiences in pyruvate dehydrogenase and dihydrolipoyltransacetylase (the EIp and E2p components of the pyruvate complex) and failure to synthesize lipoamide dehydrogenase (the $\mathrm{E}_{3}$ components of both complexes). These deletion strains also behaved as if they lacked the general aromatic permease (aroP), and SM5I, which requires nicotinate, was probably deleted for the nadC gene. Genetic studies confirmed that these strains were deleted in the leu-aziA-nadCaroP-aceE,aceF,lpd-pan region. The results also indicated that the gene-proteinrelationships of the $\alpha$-keto acid dehydrogenase complexes are similar in $S$. typhimurium and $E$. coli.
\end{abstract}

\section{INTRODUCTION}

The pyruvate and $\alpha$-ketoglutarate dehydrogenase complexes of Escherichia coli $\mathrm{KI} 2$ are multienzyme complexes containing dehydrogenase (EI), transacylase (E2) and lipoamide dehydrogenase (E3) components. They catalyse the oxidative decarboxylation of pyruvate or $\alpha$-ketoglutarate and mutants lacking these activities require acetate or succinate respectively for aerobic growth on glucose. Genetic studies have established the existence of two pairs of closely-linked structural genes for the EI and E2 components, aceE (EIp) and aceF (E2p) at $2 \mathrm{~min}$ and $s u c A(\mathrm{EI} \mathrm{kg})$ and $s u c B\left(\mathrm{E}_{2} \mathrm{~kg}\right)$ at $\mathrm{I} 6 \mathrm{~min}$ in the $E$. coli linkage map (Taylor \& Trotter, 1972). Recently, mutants lacking lipoamide dehydrogenase ( $\left.E_{3}\right)$ activity have been isolated (Guest \& Creaghan, 1972, 1973, 1974; Guest, 1974; Alwine, Russell \& Murray, 1973). Studies with these have indicated that a single gene (lpd), adjacent to the distal gene $(a c e F)$ of the ace region, specifies the $\mathrm{E}_{3}$ components of both multienzyme complexes.

The gene-protein relationships for the $\alpha$-keto acid dehydrogenase complexes of Salmon- 
ella typhimurium LT2 have not been investigated previously. However, two deletion strains, SMI 6 and SM5I, have been reported to lack $\alpha$-ketoglutarate dehydrogenase (EI kg), lipoamide dehydrogenase $\left(\mathrm{E}_{3}\right)$ and overall $\alpha$-ketoglutarate dehydrogenase complex activities (CarrilloCastaneda \& Ortega, 1970). These strains required lysine plus methionine for growth on glucose, they lacked phosphoenolpyruvate carboxykinase activity, they were resistant to low concentrations of streptomycin and one of them (SM5I) also required nicotinate. It was suggested, as a result of genetic studies, that they were deleted in the segment of the $S$. typhimurium chromosome corresponding to the $s u c A$ to nadA region of E. coli. This conclusion implies that there is an lpd gene linked to suc in $S$. typhimurium and hence a different organization of the genes for the $\alpha$-keto acid dehydrogenase complexes compared with $E$. coli. To investigate this possibility, representative ace and suc mutants of $S$. typhimurium have been isolated. Biochemical and genetic studies with these and with the deletion strains, kindly provided by $\mathrm{Dr}$ M. Ortega, now indicate that the gene-protein relationships of the $\alpha$-keto acid dehydrogenase complexes are similar in both organisms.

\section{METHODS}

Bacterial strains. Mutants requiring acetate and succinate were isolated in Salmonella typhimurium LT2 which was obtained from Dr D. A. Smith. The deletion strains SMI 6 and SM5I were spontaneous auxotrophic mutants found to be resistant to low concentrations of streptomycin $(20 \mu \mathrm{g} / \mathrm{ml})$ (Carrillo-Castaneda \& Ortega, 1970). Other strains of

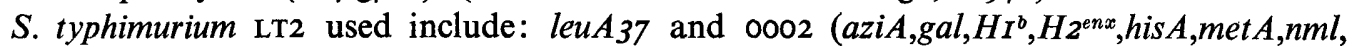
rha,trpB) from D. A. Smith; the nicotinate-requiring mutants nic-502,504,505 and 506 and the pantothenate mutant pan-50I from M. Alper: HUI I ( $($ metP,gal) and aroP 504 from P. Ayling. The following strains of Escherichia coli KI 2 were also used: W3 I IO, prototroph; WGA, (gal,trpA); representative ace and suc mutants aceE2, (A2T3); aceFro, (AIo); sucAI, (WI485sucAI) and sucBr7 (W3IrosucBI7); and the lipoamide dehydrogenase mutants ABI325lpd3, WGAlpd5, Hlpd6 and Hlpdro. Details of these strains have been described previously (Herbert \& Guest, 1969; Guest \& Creaghan, 1973).

Abbreviations. The genetic nomenclature conforms to the recommendations of Demerec, Adelberg, Clark \& Hartman (r968) and the symbols for gene loci are those used for E. coli by Taylor \& Trotter (1972). Consequently, genes determining NAD biosynthesis are designated nad rather than nic and genes determining a requirement for succinate for growth on glucose medium, e.g. genes for the dehydrogenase and transsuccinylase components of the $\alpha$-ketoglutarate complex, are designated suc. Confusion arising from the use of sut and suc to specify a gene affecting the utilization of succinate as a carbon and energy source (Sanderson, 1970, 1972) could be avoided if the first symbol, sut, was reserved for this purpose. The sut locus could correspond to the succinate dehydrogenase gene, sdh (Creaghan \& Guest, 1972) or a gene governing the transport of dicarboxylic acids, $\operatorname{dctB}$ or ct (Lo, Rayman \& Sanwal, 1972) which map near gal in E. coli KI2.

Media. The citrate-free medium of Herbert \& Guest (1970) was used with glucose $(0.2$ and $0.4 \%)$, acetate $(50 \mathrm{~mm})$, succinate $(50 \mathrm{~mm})$ or galactose $(0.4 \%$ plus bromothymol blue at a final concentration of $0.002 \%$ ) as substrates. In the genetical studies the minimal medium $\mathrm{E}$ of Vogel \& Bonner (1956) was used but only with glucose as the substrate. Minimal media were supplemented as required with acetate $(2 \mathrm{mM})$, succinate $(2 \mathrm{mM})$, L-lysine $(40 \mu \mathrm{g} / \mathrm{ml})$, L-methionine $(20 \mu \mathrm{g} / \mathrm{ml})$, other L-amino acids $(30 \mu \mathrm{g} / \mathrm{ml})$ and vitamins (Io $\mu \mathrm{g} / \mathrm{ml}$ ). L-Broth (Lennox, I955) and Bacto Nutrient Broth (Difco) were used as complete media. All media were solidified with $\mathrm{r} \cdot 5 \%$ agar (Difco) except in the preparation of 
lysates when the top and bottom layers contained 0.6 and $\mathrm{I} \cdot 0 \%$ agar respectively. Anaerobic cultures were incubated in an atmosphere of $\mathrm{H}_{2}$ with $5 \% \mathrm{CO}_{2}$.

Enzymology. Ultrasonic extracts of organisms grown in citrate-free medium containing glucose $(0.2 \%)$ plus other necessary supplements were prepared and assayed for protein content according to the methods of Guest \& Creaghan (I973). Samples of each mutant culture were tested to ensure that reversion had not occurred.

Enzyme activities were measured in the region of proportionality between initial reaction velocity and protein concentration at $25^{\circ} \mathrm{C}$ and are quoted as $\mu$ mol of substrate transformed/mg protein/h. The assay for lipoamide dehydrogenase (lpdh or $\mathrm{E}_{3}$ ), the pyruvate and $\alpha$-ketoglutarate dehydrogenase complexes (pdhc and $\mathrm{kgdhc}$ ) and the $\alpha$-ketoglutarate dehydrogenase component (Erkg) have been described previously (Creaghan \& Guest, 1972). Some indication of the pyruvate dehydrogenase (EIp) activity was obtained by using the method for EI kg with pyruvate as substrate, but it should be noted that the flavoprotein pyruvate oxidase is also active in this system. Reconstitution of the activities for overall pyruvate and $\alpha$-ketoglutarate dehydrogenase complexes was measured by mixing extracts of mutants defective in one or more components in pairs, or with purified $\mathrm{E}_{3}$ components according to the complementation assay described previously (Guest \& Creaghan, 1973).

Immunology. The preparation of antiserum raised against purified lipoamide dehydrogenase from $E$. coli B and the methods used for immunodiffusion in agarose have been described previously (Guest \& Creaghan, 1974). In quantitative experiments one unit of lipoamide dehydrogenase was defined as the amount which oxidized I $\mu \mathrm{mol}$ dihydrolipoate in I $\mathrm{h}$ under the conditions of the assay. Then, I unit of antiserum was defined as the amount neutralizing I unit of enzyme. Antiserum was assayed by incubating graded amounts with $E$. coli KI 2 extracts containing 2 to 3 units of lpdh for $20 \mathrm{~min}$ at room temperature in a final volume of $0.25 \mathrm{ml}$ saline. After centrifuging ( $20 \mathrm{~min}$, $10000 \mathrm{~g}$ at $4{ }^{\circ} \mathrm{C}$ ) to remove precipitated antibody-antigen complex the lpdh activity remaining in the supernatant fluid was assayed. A similar procedure was adopted in experiments in which antiserum was pretreated with bacterial extracts. Antiserum (approximately 3 units in a final volume of $0.3 \mathrm{ml}$ ) was incubated for $20 \mathrm{~min}$ at room temperature with an amount of bacterial extract (usually 2 to $2.5 \mathrm{mg}$ protein) which would normally remove $90 \%$ of the antibody after centrifuging. The residual antibody activity in $0.2 \mathrm{ml}$ of the supernatant fluid was then assayed by the method described above.

Isolation of mutants. Mutants of $S$. typhimurium requiring acetate or succinate for aerobic growth in glucose minimal medium were isolated following treatment with $N$-methyl- $N^{\prime}$-nitro- $N$-nitrosoguanidine according to the methods of Roth (1970) and Guest \& Creaghan (1973). Treated cultures were expressed in the presence of acetate plus succinate ( $2 \mathrm{mM}$ of each), selected with penicillin in the absence of these supplements and mutants detected by replica-plating. Mutants with a variety of different phenotypes were defined by further nutritional tests and from these, representative ace (s8) and suc (s6) were chosen for further study. The final characterization of these mutants was based on enzymological studies.

Transduction with phage $P_{22}$ and linkage analysis. Phage $P_{22}$ lysates were prepared by confluent lysis in nutrient agar overlayers on L-agar plates. Soft layers seeded with $5 \times 10^{8}$ bacteria of donor strain and $10^{6}$ phage were incubated at $37^{\circ} \mathrm{C}$ for $\mathrm{I} 6 \mathrm{~h}$. The top layers were collected, shaken with nutrient broth plus chloroform, and stood for $8 \mathrm{~h}$ at $2{ }^{\circ} \mathrm{C}$ before centrifuging to remove agar. The supernatant lysates were titrated with $S$. typhimurium LT2 as indicator and generally contained between $5 \times 10^{10}$ and $5 \times 10^{11}$ p.f.u. $/ \mathrm{ml}$. 
Phages P22 and P22int4 were used in some experiments, but a derivative of P22, HTro4/2, which gives higher frequencies of transduction (Schmieger, 1972), was used routinely. Transduction mixtures contained $4 \times 10^{8}$ stationary phase recipient organisms and $4 \times 10^{9}$ phage in a final volume of $2 \mathrm{ml}$ nutrient broth. After incubating for $20 \mathrm{~min}$ at $37^{\circ} \mathrm{C}$, appropriate dilutions in nutrient broth were plated directly on selective medium. Selective media were enriched with Bacto Nutrient Broth (I \%, v/v) except for glucosebased media, and transductant colonies were scored after 2 to 5 days, depending on the medium.

Transductants were purified on the corresponding selective medium before investigating the segregation of unselected markers by replica-plating on non-permissive and permissive media. Glucose-based media were used for selecting and scoring Leu, Pan and Nad markers. To limit the inoculum size and vitamin transfer in scoring the Nad and Pan markers two rounds of replica-plating were performed, in which the first replica-plate was used immediately as the master plate in the second round. Ace ${ }^{+}$and $\mathrm{Suc}^{+}$transductants were selected on succinate and acetate minimal media respectively, and unselected Ace and Suc markers were scored on the same media and also on glucose-based media. Galactose minimal medium was used for selecting and scoring the fermentation marker. Tests for resistance to azide were performed on nutrient agar containing sodium azide ( $3 \mathrm{~mm})$. $\mathrm{Azi}^{\mathrm{R}}$ transductants were selected on this medium, but only after the transduced cultures had been centrifuged, resuspended in fresh broth and incubated for $2 \mathrm{~h}$ at $37^{\circ} \mathrm{C}$ to allow expression of this characteristic. AroP and MetP were scored by radial streaking of saline suspensions of test colonies on plates of glucose medium and placing a filter paper disc impregnated with $0.02 \mu \mathrm{mol}$ azaserine (o-diazo-acetyl-L-serine) for AroP or $3 \mu \mathrm{mol}$ or $\alpha$-methyl-DL-methionine for MetP, at the centre of the plate. Resistance to low concentrations of streptomycin was tested on L-agar containing streptomycin sulphate $(20 \mu \mathrm{g} / \mathrm{ml})$. Chlorate resistance was tested by plating on nutrient agar containing glucose $(0.2 \%)$ and $\mathrm{KClO}_{3}(0 . \mathrm{I} \%)$ and incubating anaerobically. The AroG phenotype was determined by plating on glucose minimal medium supplemented with L-tyrosine $(28 \mu \mathrm{g} / \mathrm{ml})$ plus L-tryptophan $(35 \mu \mathrm{g} / \mathrm{ml})$; on this medium aroG mutants fail to grow because two of the three DAHP synthetases are repressed and the phenylalanine-repressible enzyme (the aro $G$ gene product) is defective.

Materials. Purified pig heart lipoamide dehydrogenase was from Sigma and a sample of the E. coli B enzyme was kindly provided by Dr C. H. Williams Jun. (Department of Biochemistry, University of Michigan, Ann Arbor, Michigan, U.S.A.). DL-Dihydro- $\alpha$ lipoate was prepared by the method of Gunsalus \& Razzell (I957). The sources of some other materials were: 3-acetyl NAD, Boehringer, Männheim, Germany; azaserine, Calbiochem; and $\alpha$-methyl-DL-methionine, Sigma.

\section{RESULTS}

\section{Nutritional and other properties of mutants}

Representative ace and suc mutants of Salmonella typhimurium LT2 were selected from a spectrum of different mutants requiring either acetate or succinate for aerobic growth on glucose (see Methods). The ace mutant ( $\mathrm{s} 8$ ) was characterized by a requirement for acetate for aerobic growth on both glucose and succinate minimal media and an ability to grow on unsupplemented acetate minimal medium (Table I). The suc mutant (s6) required succinate or lysine plus methionine for aerobic growth on glucose and would not grow on succinate or acetate minimal media (Table I). Neither mutant responded to supplements of 
Table I. Growth of Salmonella typhimurium strains on different media

\begin{abstract}
Washed suspensions of organisms were streaked on plates of minimal salts media with substrates and supplements as indicated (Io $\mu \mathrm{g}$ nicotinic acid/ml was added to all media for SM5I). Growth recorded after $48 \mathrm{~h}$ was scored as follows: ++ , very good; + , good; \pm , poor; - , none. No growth was obtained with any of the strains with glucose medium supplemented with lactate, citrate, fumarate, glutamate or aspartate, or when these compounds were used as sole carbon and energy sources.
\end{abstract}

Growth of strain:

Substrate and supplement

Glucose

Glucose (anaerobic)

Glucose + acetate

Glucose+succinate

Glucose + acetate + succinate

Glucose + lysine + methionine

Glucose + lysine + methionine + acetate

Glucose + lipoate

Succinate

Succinate + acetate

Acetate

$\begin{array}{ccccc}\begin{array}{c}\text { LT2 } \\ \text { (parent) }\end{array} & \begin{array}{c}\text { s8 } \\ (\text { ace })\end{array} & \begin{array}{c}\text { s6 } \\ (\text { suc })\end{array} & \text { sMI6 } & \text { SM5I } \\ ++ & - & - & - & - \\ + & + & + & + & + \\ ++ & + & - & + & + \\ ++ & - & + & - & - \\ ++ & + & + & + & + \\ ++ & - & + & \pm & \pm \\ ++ & + & + & + & + \\ ++ & - & - & - & - \\ ++ & - & - & - & - \\ ++ & + & - & - & - \\ \pm & \pm & - & - & -\end{array}$

lipoate, lactate, fumarate, citrate, glutamate or aspartate on glucose aerobically, but they grew anaerobically on unsupplemented glucose medium. The mutants failed to use lactate, citrate, fumarate, glutamate and aspartate as substrates; fumarate and the two amino acids were also very poor substrates for the parental strain. These responses were confirmed by growth tests in liquid media and the results clearly resembled those obtained with the corresponding mutants of $E$. coli.

Tests with the deletion strains, SMI6 and SM5I, confirmed previous observations that they required lysine plus methionine for aerobic growth on glucose but grew anaerobically without supplements (Table $\mathrm{I}$ ), that they would not use succinate as a carbon source, were resistant to streptomycin $(20 \mu \mathrm{g} / \mathrm{ml})$ and that SM5I required nicotinate (Carrillo-Castaneda \& Ortega, 1970). However, the response to lysine plus methionine was very poor and there was no response to succinate, which replaces these amino acids with suc mutants of $E$. coli (Herbert \& Guest, 1968). Further tests showed that good growth could be obtained with a single supplement of acetate, but unlike typical ace mutants they could not grow on acetate-supplemented succinate medium or acetate minimal medium (Table I). Growth tests in liquid media showed that the response to acetate could be improved by further supplements of succinate or, better, lysine plus methionine (Fig. I). The deletion strains were similar in all respects except for the nicotinate requirement of SM5I.

The phenotypes of SMI 6 and SM5I were further investigated in an attempt to establish the position and extent of their deletions. In $S$. typhimurium and $E$. coli the nadA gene is often deleted with the aroG, gal and chlD genes but deletions involving nadA and the suc region have not been found (Stouthamer, I969; Sanderson, 1972; Shapiro \& Adhya, 1969). Neither deletion strain was AroG-, $\mathrm{Gal}^{-}$or $\mathrm{Chl}^{\mathrm{R}}$. Further tests, based on the possibility that the strains were deleted for ace and adjacent genes showed them to be $\mathrm{Azi}^{\mathrm{s}}$ and MetP+ but AroP-, i.e. lacking the general aromatic amino acid permease (Ames \& Roth, 1968; Brown, 1970). It was thus concluded that SMI 6 and SM5I are deleted for aroP and at least one ace gene and that the nicotinate requirement of SM5I stems from the simultaneous deletion of a nad gene, probably nadC which is close to aroP in E. coli (Guest, 1974). 


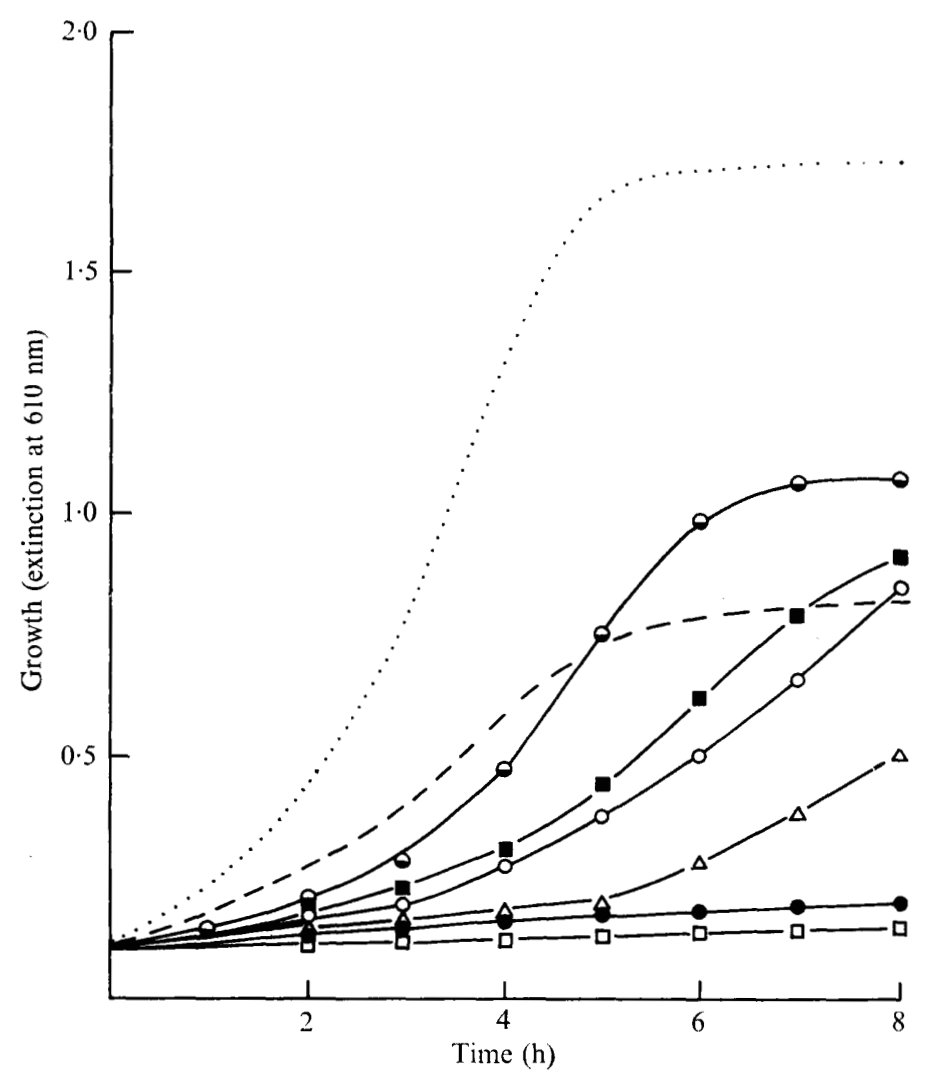

Fig. I. Growth of Salmonella typhimurium LT2 and the deletion strain SMI6. Cultures were shaken at $37^{\circ} \mathrm{C}$ in $250 \mathrm{ml}$ Erlenmeyer flasks fitted with optically matched side-arms. Each flask contained Io $\mathrm{ml}$ citrate-free medium plus glucose $(0.4 \%, \mathrm{w} / \mathrm{v})$ inoculated with $0.2 \mathrm{ml}$ of a washed suspension of organisms (grown for $16 \mathrm{~h}$ in the same medium plus acetate and succinate for SMI6) to give an initial extinction at $610 \mathrm{~nm}$ of $0.1\left(10^{8}\right.$ bacteria/ml $)$. Anaerobic growth was measured in sealed flasks containing an atmosphere of $\mathrm{H}_{2}$ with $5 \% \mathrm{CO}_{2} . \cdots$, Aerobic growth of LT2 with or without acetate + succinate; - - - , anaerobic growth of LT2 without supplements. - ${ }_{-}$, Growth of the deletion strain SMI6: aerobically with no supplements or succinate ( $\square$ ), lysine + methionine (๑), acetate $(O)$, acetate + succinate $(\square)$, or acetate +lysine + methionine $(\ominus)$; and anaerobically with no supplements $(\triangle)$.

Attempts were made to classify the nad lesion of SM5I by nutritional tests in liquid media using depleted inocula of SM5I and well-characterized nadA and nadC mutants of $E$. coli. According to Gholson, Tritz, Matney \& Andreoli (I969), nadC mutants, which lack quinolinate phosphoribosyltransferase, should respond to nicotinate but not quinolinate, whereas nadA and nadB mutants with early blocks in NAD biosynthesis should respond to both supplements. This could only be demonstrated with poor reproducibility for a very narrow range of quinolinate concentrations using the $E$. coli strains and the results with SM5I were inconclusive. The main problem was that the nadA mutants required much higher concentrations of quinolinate $(20 \mu \mathrm{g} / \mathrm{ml})$ compared with nicotinate $(0.1 \mu \mathrm{g} / \mathrm{ml})$ to obtain a good response and it was difficult to assess whether responses to quinolinate were simply due to its decarboxylation to nicotinate. 
Table 2. Specific activities of the pyruvate and $\alpha$-ketoglutarate dehydrogenase complexes and related enzymes

Organisms were grown in citrate-free medium with glucose $(0.2 \%, \mathrm{w} / \mathrm{v})$, and acetate $(2 \mathrm{~mm})$, succinate (2 mM) and nicotinic acid (10 $\mu \mathrm{g} / \mathrm{ml})$ as required. The enzymes were assayed in ultrasonic extracts as described in Methods and the average activities for determinations with at least two different extracts are quoted. Specific activities are recorded as $\mu \mathrm{mol}$ of substrate transformed $/ \mathrm{mg}$ protein/h. Abbreviations: kgdhc $=\alpha$-ketoglutarate dehydrogenase complex; Eıkg $=\alpha$-ketoglutarate dehydrogenase; pdhc $=$ activity of the overall pyruvate dehydrogenase complex; Erp = pyruvate dehydrogenase plus oxidase; $\mathrm{E}_{3}=$ lipoamide dehydrogenase.

$\quad$ Strain
LT2 (prototroph)
SMI6
SMI6TI (prototroph)
SM5I
SM5ITI (prototroph)
S8 (ace)
S6 (suc)

\begin{tabular}{|c|c|c|c|c|}
\hline kgdhc & EIkg & pdhc & EIp & E3 \\
\hline$I \cdot 40$ & $4 \cdot 30$ & $2 \cdot 60$ & $I \cdot 22$ & I. IO \\
\hline$<0.0$ I & $1 \cdot 32$ & $<0.01$ & 0.46 & $<0.01$ \\
\hline 0.54 & $2 \cdot 22$ & $2 \cdot 17$ & $1 \cdot 33$ & I.OI \\
\hline$<0.01$ & $1 \cdot 43$ & $<0.01$ & 0.63 & $<0.01$ \\
\hline I.04 & $2 \cdot 61$ & $2 \cdot 90$ & 0.83 & I.09 \\
\hline$I \cdot 26$ & 2.08 & 0.18 & 0.75 & 0.65 \\
\hline$<0.01$ & $<0.10$ & $\mathrm{I} \cdot 68$ & 0.98 & I. I I \\
\hline
\end{tabular}

\section{Table 3. Complementation between extracts of Salmonella typhimurium mutants and Escherichia coli ace and suc mutants}

The pdhc activities of mixtures of crude extracts containing $0.4 \mathrm{mg}$ protein of the $S$. typhimurium strains plus an equal amount of the $E$. coli ace mutant in $1 \mathrm{ml}$ of reaction mixture were measured by the complementation assay (see Methods). The kgdhc activities were measured with equal $0.3 \mathrm{mg}$ protein mixtures of test strains with $E$. coli suc mutants. Activities are expressed as total activity in the sample in $\mu \mathrm{mol} / \mathrm{h}$. The combined activities of participating extracts tested separately, were between 0.04 and $0.10 \mu \mathrm{mol} / \mathrm{h}$ for pdhc and less than $0.01 \mu \mathrm{mol} / \mathrm{h}$ for $\mathrm{kgdhc}$, and these have been subtracted.

\begin{tabular}{|c|c|c|c|c|}
\hline \multirow[b]{2}{*}{ Test strain } & \multicolumn{4}{|c|}{ Activity of complex $(\mu \mathrm{mol} / \mathrm{h})$} \\
\hline & $\begin{array}{c}\text { Complementing } \\
\text { strain }\end{array}$ & $\begin{array}{c}\text { pdh } \\
\text { complex }\end{array}$ & $\begin{array}{c}\text { Complementing } \\
\text { strain }\end{array}$ & $\begin{array}{c}\text { kgdh } \\
\text { complex }\end{array}$ \\
\hline aceE2 & aceFro & 0.26 & - & - \\
\hline s8 (ace) & aceFIo & $0.5 \mathrm{I}$ & - & - \\
\hline SMI6 & aceFIo & $<0.01$ & sucAI & 0.04 \\
\hline SM5 I & aceFIO & $<0.01$ & $\operatorname{sucAI}$ & 0.04 \\
\hline s6 $(s u c)$ & - & - & sucAI & $<0.005$ \\
\hline s8 (ace) & aceE2 & $<0.01$ & - & 一 \\
\hline SMI6 & aceE2 & $<0.01$ & sucBI7 & 0.07 \\
\hline SM5I & aceE2 & $<0.01$ & sucBI7 & 0.12 \\
\hline s6 (suc) & - & - & sucBi7 & 0.04 \\
\hline $\operatorname{sucA1}$ & - & - & sucBr 7 & 0.04 \\
\hline
\end{tabular}

\section{Enzymological studies}

Ultrasonic extracts were assayed directly for the overall pyruvate dehydrogenase (pdhc) and $\alpha$-ketoglutarate dehydrogenase complex (kgdhc) activities and their components, $\alpha$-ketoglutarate dehydrogenase (EIkg) pyruvate dehydrogenase (EIp) and lipoamide dehydrogenase ( $\left.E_{3}\right)$ (Table 2). Mutant 58 had less than $10 \%$ of parental pdhc activity and a lowered EIp activity, consistent with it being an ace mutant; the kgdhc activity was little affected. Mutant $\mathrm{s} 6$ resembled a typical sucA mutant in lacking overall kgdhc and EIkg activities only. The deletion strains lacked the overall activities of both complexes, pdhc and kgdhc, they had low EIp activities, and consistent with the findings of CarrilloCastaneda \& Ortega (1970) they had no detectable lipoamide dehydrogenase (E3) activity 


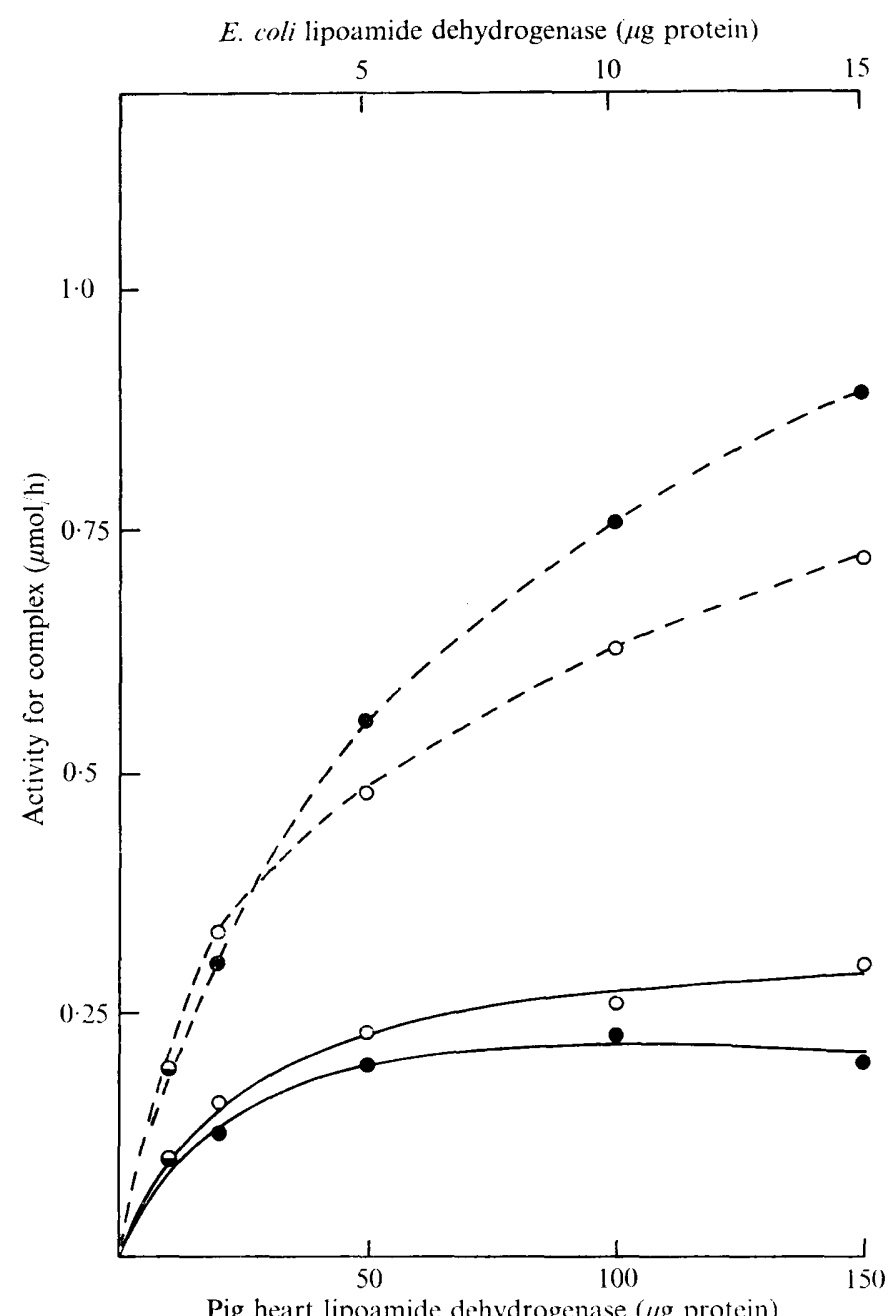

Fig. 2. Complementation of extracts of SMI 6 and SM5I for overall $\alpha$-ketoglutarate dehydrogenase complex activity by lipoamide dehydrogenase purified from pig heart (-) or E. coli в (---). Duplicate samples containing extract of SMI $6(O)$ or SM5I $(O)$ equivalent to $0.6 \mathrm{mg}$ protein were mixed with the purified enzyme and assayed for kgdhc by the complementation method.

(Table 2). However, in contrast to previous findings both strains had significant $\alpha$-ketoglutarate dehydrogenase (EI kg) activities, so it appeared that the lack of kgdhc activity stemmed from the absence of $E_{3}$ rather than a combined lack of EI kg and E3. Attempts to measure dihydrolipoyltranssuccinylase $(\mathrm{E} 2 \mathrm{~kg})$ activity by the method used for $E$. coli (Creaghan \& Guest, 1972) were unsuccessful with $S$. typhimurium LT2. It should also be noted that the EIp assay is ambiguous as it measures pyruvate dehydrogenase and also the flavoprotein pyruvate oxidase; the latter probably accounts for approximately half of the activity recorded for the wild-type. Prototrophic transductants, SMI6TI and SM5ITI, selected on glucose minimal medium with P22int4.LT2 lystate regained in a single step the activities lacking in the deletion strains (Table 2).

In the complementation studies summarized in Table 3 , the restoration of overall pdhc 


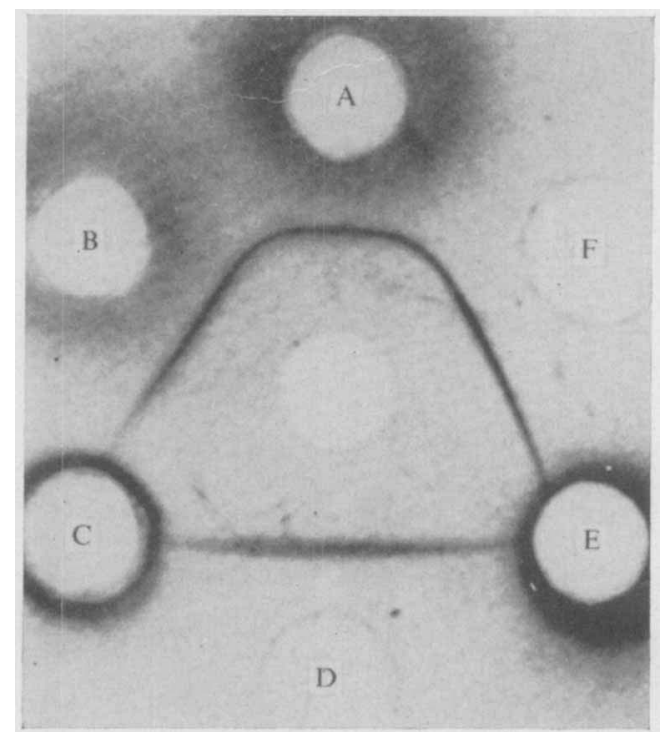

Fig. 3. Immunodiffusion in agarose with antiserum in the centre well (10 $\mu$ l of a tenfold dilution and lateral wells containing ultrasonic extract equivalent to $100 \mu \mathrm{g}$ protein of S.typhimurium LT2 (A), $E$. coli KI2 (B), SM5I (C) and SMI6(E), or I $\mu \mathrm{g}$ of lipoamide dehydrogenase purified from $E$. coli $\mathrm{B}$ (D and F). The gel was developed for $40 \mathrm{~h}$ at room temperature, washed in saline then water and dried before staining with Ponceau S.

and kgdhc activities in extracts of the $S$. typhimurium mutants by addition of standard $E$. coli ace and suc mutants was investigated. Strain $\mathrm{s} 8$ was complemented by aceFIo but not by aceE2 for pdhc activity. This strain may therefore be designated as an ace $E$ mutant. The overall kgdhc activity generated by complementation was generally low but strain $\mathrm{s} 6$ was complemented by extracts of $s u c B$ but not sucA mutants of $E$. coli (Table 3). This confirmed the earlier conclusion that $\mathbf{s} 6$ is a $\operatorname{sucA}$ mutant of $S$. typhimurium. Similar studies with SMI 6 and SM5I showed that they were complemented by sucA and sucB mutants but not by aceE and aceF mutants (Table 3). Further complementation studies using purified lipoamide dehydrogenases from $E$. coli B and pig heart (Fig. 2) also indicated that the deletion strains contain both the EIkg and the E2kg components because overall kgdhc activity was restored. However, no overall pdhc activity was reconstituted, confirming that the deletion strains lack one and probably both of the EIp and E2p components of the pdh complex as well as the lipoamide dehydrogenase (E3) activity. Similar results were obtained when an extract of an ace,suc double-amber mutant, wGAaceE64sucA35 (Guest \& Creaghan I973), was used as the source of lipoamide dehydrogenase activity for complementation.

\section{Immunological studies}

The deletion strains were further characterized in immunological studies using a rabbit antiserum raised against purified $E$. coli lipoamide dehydrogenase. In double diffusion experiments with this antiserum, crude extracts of $S$. typhimurium LT2 (Fig. 3A) gave a single precipitin line which fused completely with the lines developed by crude extracts of E. coli KI2 (Fig. 3B) and purified lipoamide dehydrogenase (Fig. 3F). This indication of complete immunological identity between the lipoamide dehydrogenases of the two species was confirmed in the quantitative tests illustrated in Fig. 4. These titrations showed that the 


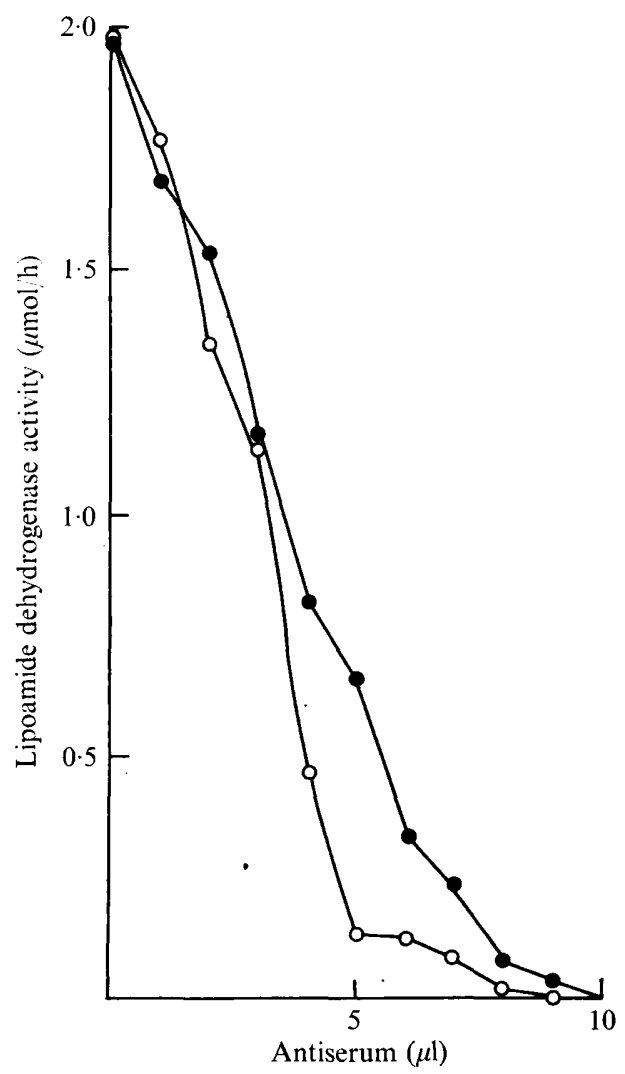

Fig. 4. The effect of antiserum on the lipoamide dehydrogenase activities of ultrasonic extracts of $S$. typhimurium LT2 (1.6 mg protein) and $O, E$. coli $\mathrm{W}_{3}$ I IO (I.4 mg protein). Samples containing 2 units of enzyme activity were incubated with antiserum in buffered saline and after centrifuging the lipoamide dehydrogenase activity remaining in the supernatant fluid was assayed (see Methods).

Table 4. Test for neutralization of lipoamide dehydrogenase antiserum by extracts of $S$. typhimurium and $E$. coli strains

Samples of antiserum (equivalent to $2 \cdot 3$ units before preincubation with $\mathrm{I} \cdot 5 \mathrm{mg}$ protein in extracts of the test strain and centrifuging) were assayed for residual activity by measuring their effect on extract of wild-type $E$. coli containing 2.5 units of lipoamide dehydrogenase. Representative $C R M+$ and $C R M-l p d$ mutants of $E$. coli were used as controls.

Antiserum

(units

Test strain remaining)

None
SMI6
SM5I
Hlpd6 $(C R M-)$
HlpdIo $(C R M-)$
ABI325lpd3 $(C R M+)$
WGAlpd5 $(C R M+)$

$$
\begin{aligned}
& 2 \cdot 3 \\
& 2 \cdot 5 \\
& 2 \cdot 3 \\
& 2 \cdot 0 \\
& 2 \cdot 2 \\
& 0 \cdot 2 \\
& I \cdot 0
\end{aligned}
$$


Table 5. Linkage relationships in the regions of the aceE and sucA genes of Salmonella typhimurium

All transductions were mediated by a high-frequency transducing derivative of phage $\mathrm{P}_{22}$, HTI04/2, except crosses IA and IB where P22int4 was used.

\begin{tabular}{|c|c|c|c|c|c|c|c|}
\hline Cross & Donor & Recipient & Selection & $\begin{array}{c}\text { Trans- } \\
\text { ductants } / \\
10^{6} \text { phage }\end{array}$ & $\begin{array}{l}\text { Number } \\
\text { scored }\end{array}$ & $\begin{array}{c}\text { Unselected } \\
\text { donor } \\
\text { marker }\end{array}$ & $\begin{array}{c}\text { Cotrans- } \\
\text { duction } \\
\text { frequency } \\
(\%)\end{array}$ \\
\hline I A & $\operatorname{leu} A_{37}$ & s8 & $\mathrm{Ace}^{+}$ & 0.5 & 98 & Leu $^{-}$ & $<\mathrm{I}$ \\
\hline IB & s8 & $\operatorname{leu} A_{37}$ & $\mathrm{Leu}^{+}$ & $0 \cdot 1$ & 70 & $\mathrm{Ace}^{-}$ & $<2$ \\
\hline 2 & pan-50I & s8 & $\mathrm{Ace}^{+}$ & IO & 150 & Pan- $^{-}$ & $<$I \\
\hline 3 & 0002 & s8 & $\mathrm{Ace}^{+}$ & 4 & 100 & $\mathrm{Azi}^{\mathrm{R}}$ & I4 \\
\hline 4 & aroP504 & s8 & $\mathrm{Ace}^{+}$ & 20 & 200 & AroP- & 72 \\
\hline 5 & HUI I I & s8 & $\mathrm{Ace}^{+}$ & 5 & 50 & MetP- & $<2$ \\
\hline 6 & nic-502 & s8 & $\mathrm{Ace}^{+}$ & 12 & 100 & $\mathrm{Nad}^{-}$ & $<1$ \\
\hline 7 & nic-505 & s8 & $\mathrm{Ace}^{+}$ & I 5 & 100 & $\mathrm{Nad}^{-}$ & $<$I \\
\hline $8 \mathbf{A}$ & HUI 1 I & s6 & Suc $^{+}$ & 28 & 100 & $\mathrm{Gal}^{-}$ & $<$I \\
\hline $8 B$ & s6 & HUIII & $\mathrm{Gal}^{+}$ & 2 & 100 & Suc $^{-}$ & $<$I \\
\hline $9 A$ & nic-502 & s6 & $\mathrm{Suc}^{+}$ & 2 & 200 & $\mathrm{Nad}^{-}$ & 12 \\
\hline $9 B$ & s6 & nic-502 & $\mathrm{Nad}^{+}$ & I & 100 & Suc ${ }^{-}$ & $<$I \\
\hline IO & nic- 505 & s6 & $\mathrm{Suc}^{+}$ & 4 & 100 & $\mathrm{Nad}^{-}$ & $<$I \\
\hline I I & 0002 & aroP5O4 & $\mathrm{Azi}^{\mathbf{R}}$ & I I & 100 & AroP- & 39 \\
\hline I 2 & 0002 & leuA37 & $\mathrm{Leu}^{+}$ & 8 & 120 & $\mathrm{Azi}^{\mathrm{R}}$ & 3 \\
\hline I3 & aroP5O4 & $\operatorname{leu} A 37$ & $\mathrm{Leu}^{+}$ & 16 & 210 & AroP- & I \\
\hline I4A & 0002 & nic-502 & $\mathrm{Nad}^{+}$ & I I & 100 & $\mathrm{Gal}^{-}$ & 27 \\
\hline I4B & nic-502 & 0002 & $\mathrm{Gal}^{+}$ & 5 & 100 & $\mathrm{Nad}^{-}$ & 20 \\
\hline 15 & 0002 & nic-505 & $\mathrm{Nad}^{+}$ & 20 & 100 & $\mathrm{Gal}^{-}$ & $<I$ \\
\hline
\end{tabular}

antiserum was almost equally effective in neutralizing the E. coli and S. typhimurium enzymes. Tests with the deletion strains, SM5I and SMI6, gave no detectable precipitin lines (Fig. ${ }_{3} \mathrm{C}, \mathrm{E}$ ), indicating the absence of cross-reacting material $(C R M-)$. In similar tests the prototrophic transductants SMI6TI and SM5ITI and mutants 56 and s8 were indistinguishable from wild type. Further quantitative tests with the deletion strains and representative $C R M+$ and $C R M$ - lpd mutants of $E$. coli showed that the activity of the antiserum was virtually unaffected by preincubation with extracts of the deletion strains and the $C R M$ - mutant of E. coli (Table 4). The lack of lipoamide dehydrogenase activity and cross-reacting material would therefore suggest that the deletions extend into the lpd gene or into some element controlling the expression of the lpd gene.

\section{Genetic studies}

The results of P22-mediated transductions involving $a c e E$, sucA and several other mutants of S. typhimurium are shown in Table 5. Cotransduction was observed for aceE with aziA (cross 3) and, at a higher frequency, with $\operatorname{aroP}$ (cross 4) but no linkage was detected with leuA (cross I), pan (cross 2), metP (cross 5) or with either of two classes of nad mutant (crosses 6 and 7). Considered with the cotransduction frequencies observed for leuA with aziA (cross I2), leuA with aroP (cross I3) and aziA with aroP (cross II), these linkage data are consistent only with the gene order leuA-aziA-aroP-aceE, as illustrated in Fig. 5. The sucA marker was linked to $\operatorname{nadA}$ (cross $9 \mathrm{~A}$ ) but not to $\mathrm{gal}$ (cross I4), and since nadA is linked to $\mathrm{gal}$ (cross I4) and the relative orientation of nadA and $\mathrm{gal}$ has been established by studies with deletions (Stouthamer, 1969) the order sucA-nadA-gal can be deduced (Fig. 5). The failure to detect linkage between sucA and nadA with s6 as donor (cross $9 \mathrm{~B}$ ) was confirmed but not investigated further. A total of four nad mutants, kindly provided by Dr M. Alper, 


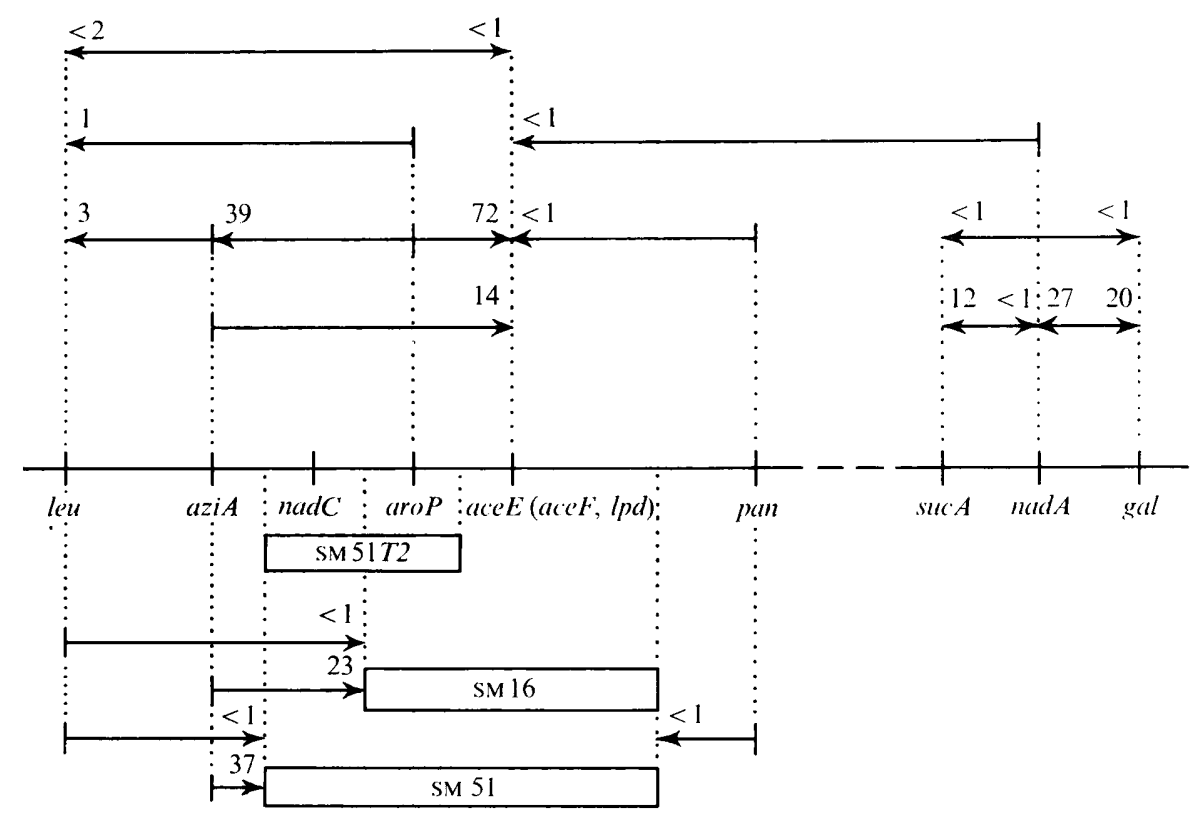

Fig. 5. Linkage map showing the position of ace and suc loci with respect to other loci. Also shown are the proposed extremities of the SMI6, SM5I and SM5IT2 deletions. Cotransduction frequencies are given as the number of recombinants inheriting the unselected marker expressed as a percentage of the number of selected transductants examined. For each cross the corresponding frequency is placed near the head of the arrow pointing to the selected marker.

was examined. Two of them, nic-502 and nic-506, were designated nadA by virtue of their linkage to $s u c A$ and gal and by comparison with the distribution of nad genes in $E$. coli (Taylor \& Trotter, 1972). The others, nic-504 and nic-505, exhibited no linkage with sucA (cross Io), gal (cross I5) or ace (cross 7) and, again by analogy with E. coli, are unlikely to be $\operatorname{nadA}$ or nadC mutants.

The enzymological studies with the deletion strains indicated that they possess Ace- $\mathrm{Lpd}^{-}$ phenotypes; however, no independent selection procedures for $\mathrm{Ace}^{+}$and $\mathrm{Lpd}^{+}$transductants could be devised. Using SMI 6 as recipient, $\mathrm{Ace}^{+} \mathrm{Lpd}^{+}$transductants were readily selected on glucose minimal medium. With SM5I, on the other hand, separate selections for Ace ${ }^{+} \mathrm{Lpd}^{+}$ and $\mathrm{Nad}^{+}$transductants were possible using glucose + nicotinate and glucose + lysine + methionine + acetate, in addition to a combined selection for $\mathrm{Nad}^{+} \mathrm{Ace}^{+} \mathrm{Lpd}^{+}$transductants. In crosses with wild-type donors similar transduction frequencies were observed in all three selections (range, I to Io per $10^{6}$ phage in different experiments). Tests with $900 \mathrm{Ace}^{+} \mathrm{Lpd}^{+}$ and $450 \mathrm{Nad}^{+}$transductants of SM5I yielded only one transductant in which segregation of the unselected characteristic had occurred. This strain, SM5IT2, was an Ace ${ }^{+} \mathrm{Ld}^{+}$ transductant which proved to be $\mathrm{Nad}^{-}$. It would therefore appear that all three characteristics are generally inherited in a single step. It is assumed that SM5IT2 arose following some kind of aberrant recombination event. The prototrophic transductants of SMI 6 and SM5I were also found to be AroP ${ }^{+}$and sensitive to low concentrations of streptomycin. By contrast, SM5IT2 became Ace ${ }^{+} \mathrm{Lpd}^{+}$but remained AroP- and resistant to low concentrations of streptomycin as well as $\mathrm{Nad}^{-}$. This suggests that the $n a d$ and aroP genes and a gene conferring resistance to low concentrations of streptomycin are clustered to one side of 
Table 6. Linkage relationships between the deletion strains SMI6 and SM5I

\begin{tabular}{|c|c|c|c|c|c|c|c|}
\hline & & & ind other markers & & & & \\
\hline Cross & Donor* & Recipient* & Selection & $\begin{array}{l}\text { Trans- } \\
\text { ductants/ } \\
10^{6} \text { phage }\end{array}$ & $\begin{array}{l}\text { Number } \\
\text { scored }\end{array}$ & $\begin{array}{c}\text { Un- } \\
\text { selected } \\
\text { donor } \\
\text { marker }\end{array}$ & $\begin{array}{l}\text { Cotrans- } \\
\text { duction } \\
\text { frequency } \\
(\%)\end{array}$ \\
\hline 16,17 & leuA37 & SMI6, SM5I & $\mathrm{Ace}^{+} \mathrm{Lpd}^{+}\left(\mathrm{Nad}^{+}\right)$ & I & 330 & $\mathrm{Leu}^{-}$ & $<0.3$ \\
\hline 18,19 & pan-50I & SMI6, SM5I & $\mathrm{Ace}^{+} \mathrm{Lpd}^{+}\left(\mathrm{Nad}^{+}\right)$ & I & 200 & $\mathrm{Pan}^{-}$ & $<0.5$ \\
\hline 20 & 0002 & SMI 6 & $\mathrm{Ace}^{+} \mathbf{L p d}^{+}$ & 2 & 100 & $\mathrm{Azi}^{\mathrm{R}}$ & 23 \\
\hline $2 \mathrm{I}$ & 0002 & SM51 & $\mathrm{Ace}^{+} \mathrm{Lpd}^{+} \mathrm{Nad}^{+}$ & 8 & 100 & $\mathrm{Azi}^{R}$ & 37 \\
\hline 22,23 & aroP504 & SMI6, SM5I & $\mathrm{Ace}^{+} \mathrm{Lpd}^{+}\left(\mathrm{Nad}^{+}\right)$ & I & 100 & AroP- $^{-}$ & 100 \\
\hline 24 & s8 & SM16 & $\mathrm{Ace}^{+} \mathbf{L p d}^{+}$ & $<0.002$ & - & - & - \\
\hline 25 & s8 & SM5I & $\mathrm{Ace}^{+} \mathrm{Lpd}^{+}$ & $<0.002$ & - & - & - \\
\hline & & & $\mathrm{Nad}^{+}$ & 0.2 & 50 & Ace $^{-}$ & 100 \\
\hline 26,27 & SMI6, SM5I & s8 & $\mathrm{Ace}^{+}$ & $<0.002$ & - & - & - \\
\hline 28 & & SMI6 & $\mathrm{Ace}^{+} \mathrm{Lpd}^{+}$ & 0.6 & - & - & - \\
\hline 29 & s6 & SM5I & Ace $^{+} \mathbf{L p d}^{+}$ & 0.8 & - & - & - \\
\hline & & & $\mathrm{Nad}^{+}$ & 0.8 & - & - & - \\
\hline $30,3 \mathrm{I}$ & SMI6, SM5I & s6 & Suc $^{+}$ & 9 & - & - & - \\
\hline
\end{tabular}

* Where two donor or recipient strains are indicated, two crosses were performed with similar results.

the ace region. Furthermore, since the gene order aziA-aroP-ace $E$ has already been indicated, a consideration of the phenotypes of SMI6, SM5I and SM5IT2 places the nad gene between azi $A$ and aroP thus: aziA-nad-aroP-aceE.

Transductions between the deletion strains and a variety of donor strains are summarized in Table 6. Tests with $\mathrm{Ace}^{+} \mathrm{Lpd}^{+}$(SMI6) and $\mathrm{Nad}^{+} \mathrm{Ace}^{+} \mathrm{Lpd}^{+}$(SM5I) transductants showed no linkage with leu (crosses I6 and I7) or pan (crosses I 8 and 19) but aziA was linked to both deletions (crosses 20 and 2I). The gradient of cotransduction frequencies for SM5I $(37 \%)$, SMI $6(23 \%)$ and S8 (14\%) suggests that the SM5I deletion ends closer to aziA than the SMI 6 deletion, which in turn terminates nearer aziA than the aceE mutation of s8. This further supports the conclusion that the SM5I deletion includes a nad gene, presumably analogous to the nadC gene of $E$. coli, which lies between aziA and aroP, and that the SMI 6 deletion extends through aroP but not as far as nad. Further confirmation that the deletions include aroP came from the use of an aroP donor, because all prototrophic transductants were AroP- (Table 6, crosses 22 and 23). No Ace ${ }^{+} \mathrm{Lpd}^{+}$transductants could be obtained from either deletion strain using $\mathrm{s} 8$ as donor (Table 6, crosses 24 and 25) and although $\mathrm{Nad}^{+}$transductants of SM5I were recovered they were all Ace ${ }^{-}$. In reciprocal crosses (26 and 27) with SMI 6 and SM5I as donors no acetate-independent transductants of s8 could be recovered on enriched succinate medium. These findings confirm that both strains are deleted for aceE. By contrast, high yields of transductants $\left(\mathrm{Ace}^{+} \mathrm{Lpd}^{+}\right.$and $\mathrm{Nad}^{+}$) were obtained from the deletions using $\mathrm{s} 6$ as donor and from reciprocal crosses in which $\mathrm{Suc}^{+}$ transductants were selected on enriched acetate medium (Table 6 , crosses 28 to 31 ). This genetic evidence lends further support to the conclusion that the deletions are not in the suc region. Similar reciprocal crosses also established that the nicotinic acid requirement of SM5I could not be due to the deletion of either class of nad gene represented by nic-502 and nic-505.

In connection with the reported deletion of the phosphoenolpyruvate carboxykinase gene (pck) in SMI6 and SM5I it should be noted that, contrary to the observations of CarrilloCastanedo \& Ortega (1970), single-step transductions of SM5I with LT2 as donor failed to yield products capable of using succinate or acetate as sole carbon and energy sources. None of the Ace ${ }^{+} \mathrm{Lpd}^{+}$transductants of SM5I grew with either of these substrates and even 
after a second transduction recombinants could only be recovered on succinate. With SMI 6 a small proportion of the $\mathrm{Ace}^{+} \mathrm{Lpd}^{+}$transductants could utilize succinate, but this could have been due to reversion. These results suggest that there are at least two or three unlinked defects which are affecting growth on succinate and acetate respectively. The addition of citrate promoted growth of some of the derivatives on these substrates but this complication could be connected with the general observation that all strains of $S$. typhimurium LT2 grew better in the presence of citrate, especially with acetate or dibarboxylic acids as the main substrate.

\section{DISCUSSION}

Studies with the ace and suc mutants and the deletion strains suggest that the genes determining the $\alpha$-keto acid dehydrogenase complexes are organized in a similar manner in Salmonella typhimurium LT2 and Escherichia coli KI2. Mutant \$8, identified as a pyruvate dehydrogenase (aceE) mutant, resembled comparable mutants of E. coli and was similarly situated in the leu-pan region. The sucA mutant, s6, which lacked $\alpha$-ketoglutarate dehydrogenase, was similar in all respects to the class of $E$. coli sucA mutant which requires succinate for aerobic growth on glucose but fails to grow with succinate as substrate (Herbert \& Guest, 1968); whether this latter property is a feature of some suc mutants or whether it is due to a second mutation has still to be determined. As in $E$. coli the sucA gene was situated near nadA and gal. The components of both $S$. typhimurium complexes also appeared to be sufficiently similar to those of $E$. coli to permit complementation and presumably the formation of hybrid complexes when extracts of mutants of both species were mixed. Purified $E$. coli lipoamide dehydrogenase complemented the $S$. typhimurium Erkg and E2kg components of SMI 6 and SMBI very efficiently to generate overall activity of the $\alpha$-ketoglutarate dehydrogenase complex. Furthermore, the lipoamide dehydrogenase components of the two species were immunologically indistinguishable.

Compared with PI-mediated transduction in E. coli, $\mathbf{P 2 2}$ presented certain problems initially. These were due mainly to the low frequencies of transduction observed for markers in the regions under investigation, and the relatively small size of the $P_{22}$ transducing fragment. The first problem was overcome by using one of the high-frequency transducing phages isolated by Schmieger (1972), the second became less troublesome when additional markers were brought into the analysis. If it is assumed that the molecular weights of P22 and PI DNA are $2.8 \times 10^{7}$ and $7.8 \times 10^{7}$ daltons (Clowes, 1972) and that the transducing phages carry $90 \%$ (Schmieger, 1970) and 100\% (Ikeda \& Tomizawa, 1965) as bacterial DNA respectively, then using the mapping function of Wu (1966) which relates joint transduction of markers to the distance between markers thus:

$$
\text { Frequency of cotransduction }=\left(\mathrm{I}-\frac{\text { distance between markers }}{\text { length of transducing fragment }}\right)^{3}
$$

it can be calculated that a cotransduction frequency of $\mathrm{I} \%$ with $\mathrm{P} 22$ would correspond to a frequency of $4 \mathrm{I} .6 \%$ in PI-mediated cotransduction for markers separated by the same distance.

Assuming that the corresponding markers are separated by approximately the same distances (in terms of DNA length) in E. coli and $S$. typhimurium, it is not surprising that with $\mathrm{P}_{22}$ no cotransduction was observed for aceE with leu ( $25 \%$ for $\mathrm{PI}_{\mathrm{I}}$ ), aceE with pan ( $20 \%$ for PI) or gal with sucA (36\% for PI). One exception is the observed cotransduction of aroP with leu (I \% for P22) which may not have been expected since these markers are only $30 \%$ cotransducible with PI in E. coli (Brown, 1970). This could mean that the 
markers are relatively closer in $S$. typhimurium but it should be noted that other workers have failed to detect any linkage between $a r o P$ and $l e u$ (Ames \& Roth, 1968). In other cases where linkage has been observed in both systems the cotransduction frequencies, though different, were comparable in terms of the marker separations (in base pairs) when calculated using the $\mathrm{Wu}$ relationship and a figure of $\mathrm{I} \cdot 5 \mathrm{I} \times \mathrm{IO}^{3}$ base pairs per mega-dalton of DNA. For example, cotransduction frequencies for aceE with aroP of $72 \%\left(\mathrm{P}_{22}\right)$ and $92 \%$ (PI; Guest, I974) correspond to separations of $4 . \mathrm{I}$ and $2.8\left(\times \mathrm{IO}^{3}\right.$ base pairs or 'average genes'). Likewise, the cotransduction frequencies for (a) leu with aziA at $3 \%(\mathrm{P} 22)$ and $56 \%$ (PI; Yura \& Wada, 1968) correspond to 19.4 and 13.4 ( $\times 10^{3}$ base pairs), (b) leu with aroP at $\mathrm{I} \%$ (P22) and $30 \%$ (PI; Brown, I970) correspond to $3 \mathrm{I}$ and 39 ( $\times \mathrm{IO}^{3}$ base pairs), (c) nadA with sucA at $12 \%\left(\mathrm{P}_{22}\right)$ and $63 \%$ (PI; Guest, 1974) correspond to $2 \mathrm{I}$ and $\mathrm{I} 7$ $\left(\times 10^{3}\right.$ base pairs) and $(d)$ nadA with gal at $23 \%\left(\mathrm{P}_{22}\right)$ and $80 \%\left(\mathrm{PI}_{\text {; }}\right.$ Guest, 1974$)$ correspond to 15 and 9 ( $\times 10^{3}$ base pairs) respectively. Thus it would appear that not only are the genes in the same relative order, leu-aziA-aroP-aceE and sucA-nadA-gal in S. typhimurium (Fig. 5) and in $E$. coli (Guest, 1974), but the intergenic separations could be comparable.

All the properties of the deletion strains support the conclusion that they are deleted in the aziA to pan region, rather than in the gal region as previously supposed. The nicotinate requirement of SM5I is almost certainly due to the deletion of a nad gene, presumably nadC, between aziA and aroP. The biochemical properties of SMI 6 and SM5I are most readily interpreted if the $a c e E, a c e F$ and $l p d$ genes are deleted. That the $a c e E$ gene is deleted can be inferred from the fact that no recombinants were obtained from crosses between $\mathrm{s} 8$ (aceE) and either deletion strain. No such confirmation is available for ace $F$ and $l p d$ since the corresponding point mutants have not yet been characterized in $S$. typhimurium. It therefore remains a formal possibility that the $a c e F, l p d$ or both genes are present, but their expession is in some way prevented by the deletions. This again would be most simply explained if the genes are linked and polarized as they are in E. coli: aceE-aceF-lpd. It is therefore proposed that the strains are deleted in the leu-aziA-nadC-aroP-aceE,aceF,lpd-pan region; SMI 6 between aroP and $l p d$ and SM5I between nadC and $l p d$. Similar deletions have now been isolated in $E$. coli KI2 and here the end-points can be analysed with greater precision.

One noteworthy property of the deletion strains is their ability to respond to acetate as sole supplement on glucose medium. E. coli lpd mutants which would be expected to have a comparable phenotype, do not respond to this single supplement. This could indicate that in S. typhimurium other routes of succinate biosynthesis, e.g. the reductive routes, are less severely repressed or inhibited, or alternatively that an unstable lipoamide dehydrogenase (possibly an incomplete protein) is produced by the deletion strains and this can support growth when acetate is provided.

It has been suggested previously that SMI6 and SM5I exhibit a limited resistance to streptomycin because the deletions impose a respiratory deficiency which shifts their metabolism towards anaerobiosis (Carrillo-Castaneda \& Ortega, 1970). This resistance was not observed with ace or suc mutants of $S$. typhimurium or E. coli or with lpd mutants of E. coli, which are more comparable to the deletion strains because they lack activities of both dehydrogenase complexes. Further tests seemed to rule out any connexion with the aroP lesion, because aroP mutants of $S$. typhimurium and $E$. coli were sensitive, as were aroP, ace $E$ and aroP,lpd double mutants of $E$. coli (Guest, unpublished observations). It would therefore appear that resistance to low concentrations of streptomycin is governed either by some independent marker which is deleted in both strains or by the combined effects of the deletion and some other mutation in SMI 6 and SM5I. 
The deletion strains were originally described as lacking phosphoenolpyruvate carboxykinase due to deletion of the $p c k$ gene and this was considered responsible for their inability to use succinate as sole carbon source (Carrillo-Castaneda \& Ortega, 1970). This conclusion seems unlikely since $\mathrm{C}_{4}$-dicarboxylic acids could be converted to phosphoenolpyruvate by an alternative route involving malic enzyme and phosphoenolpyruvate synthase. A more plausible explanation for failure to use succinate (and acetate) would be the absence of the $\alpha$-keto acid dehydrogenase complex activities. Unfortunately, the previous observation that prototrophic transductants regained the ability to utilize succinate (Carrillo-Castandea \& Ortega, 1970) could not be confirmed. In fact the present results suggest that the deletion strains contain one or two unlinked mutations preventing growth on succinate and yet a further mutation preventing growth on acetate. None of these mutations is likely to involve the pck gene since a functional carboxykinase is probably not obligatory for growth on succinate or acetate. If the strains have not changed since they were first examined, the reported lack of carboxykinase could be an indirect consequence of these lesions, a direct or indirect result of the deletions or it could be due to yet another mutation, presumably in the pck gene.

We wish to thank all those who have provided mutant strains used in this work. D.L. also acknowledges the receipt of a Research Studentship from the Science Research Council.

\section{REFERENCES}

Alwine, J. C., Russell, F. M. \& Murray, K. N. (I973). Characterization of an Escherichia coli mutant deficient in dihydrolipoyl dehydrogenase activity. Journal of Bacteriology II5, I-8.

AMES, G. F. \& RoTH, J. R. (I968). Hisitidine and aromatic permeases of Salmonella typhimurium. Journal of Bacteriology 98, 1742-1749.

Brown, K. D. (1970). Formation of aromatic amino acid pools in Escherichia coli K-I2. Journal of Bacteriology 104, I77-I88.

Carrillo-Castaneda, G. \& Ortega, M. V. (1970). Mutants of Salmonella typhimurium lacking phosphoenolpyruvate carboxykinase and $\alpha$-ketoglutarate dehydrogenase activities. Journal of Bacteriology 102, 524-530.

Clowes, R. C. (I972). Molecular structure of bacterial plasmids. Bacteriological Reviews 36, 36I-405.

Creaghan, I. T. \& Guest, J. R. (1972). Amber mutants of the $\alpha$-ketoglutarate dehydrogenase gene of Escherichia coli KI2. Journal of General Microbiology 71, 207-220.

Demerec, M., Adelberg, E. A., Clark, A. J. \& Hartman, P. E. (1968). A proposal for a uniform nomenclature in bacterial genetics. Journal of General Microbiology 50, I-4.

Gholson, R. K., Tritz, G. J., Matney, T. S. \& Andreoli, A. J. (1969). Mode of nicotinamide adenine dinucleotide utilization by Escherichia coli. Journal of Bacteriology 99, 895-896.

Guest, J. R. (1974). Gene-protein relationships of the $\alpha$-keto acid dehydrogenase complexes of Escherichia coli $\mathrm{kr} 2$ : chromosomal location of the lipoamide dehydrogenase gene. Journal of General Microbiology 8o, 523-532.

Guest, J. R. \& Creaghan, I. T. (I972). Lipoamide dehydrogenase mutants of Escherichia coli KI2. Biochemical Journal 130, 8P.

Guest, J. R. \& Creaghan, I. T. (I973). Gene-protein relationships of the $\alpha$-keto acid dehydrogenase complexes of Escherichia coli $\mathrm{KI2}$ : Isolation and characterization of lipoamide dehydrogenase mutants. Journal of General Microbiology 75, 197-210.

Guest, J. R. \& Creaghan, I. T. (1974). Further studies with lipoamide dehydrogenase mutants of Escherichia coli KI 2. Journal of General Microbiology 81, 237-245.

Gunsalus, I. C. \& Razzell, W. E. (1957). Preparation and assay of lipoic acid and derivatives. In Methods in Enzymology, vol. 3, pp. 94I-946. Edited by S. P. Colowick and N. O. Kaplan. New York and London: Academic Press.

Herbert, A. A. \& Guest, J. R. (1968). Biochemical and genetic studies with lysine + methionine mutants of Escherichia coli: lipoic and $\alpha$-ketoglutarate dehydrogenase-less mutants. Journal of General Microbiology 53, 363-381. 
Herbert, A. A. \& GUEST, J. R. (1969). Studies with $\alpha$-ketoglutarate dehydrogenase mutants of Escherichia coli. Molecular and General Genetics 105, 182-190.

Herbert, A. A. \& GUeST, J. R. (1970). Two mutations affecting utilization of $\mathrm{C}_{4}$-dicarboxylic acids. Journal of General Microbiology 63, 15I-I62.

IKeDA, H. \& TomizaWA, J. (1965). Transducing fragments in generalised transduction by phage PI. I. Molecular origin of the fragments. Journal of Molecular Biology 14, 85-109.

Lennox, E. S. (1955). Transduction of linked genetic characters of the host by bacteriophage PI. Virology I, 190-206.

Lo, T. C. Y., Rayman, M. K. \& Sanwal, B. D. (1972). Transport of succinate in Escherichia coli. I. Biochemical and genetic studies of transport in whole cells. Journal of Biological Chemistry 247, 6323-633I.

Rotн, J. R. (1970). Genetic techniques in studies of bacterial metabolism. In Methods in Enzymology, vol. 17 A, pp. 3-35. Edited by H. Tabor and C. W. Tabor. New York and London: Academic Press.

SANDERSON, K. E. (1970). Current linkage map of Salmonella typhimurium. Bacteriological Reviews 34, $176-193$.

SANDERSON, K. E. (1972). Linkage map of Salmonella typhimurium. Edition Iv. Bacteriological Reviews 36, $558-586$.

SCHMIEGER, H. (1970). The molecular structure of the transducing particles of Salmonella-phage P22. II. Density gradient analysis of DNA. Molecular and General Genetics 109, 323-337.

SCHMieger, H. (1972). Phage P22-mutants with increased or decreased transduction abilities. Molecular and General Genetics I19, 75-88.

Shapiro, J. A. \& AdhYA, S. L. (1969). The galactose operon of E. coli K-I2. A deletion analysis of operon structure and polarity. Genetics 62, 249-264.

Stouthamer, A. H. (1969). A genetical and biochemical study of chlorate-resistant mutants of Salmonella typhimurium. Antonie van Leeuwenhoek 35, 505-52I.

TAYLOR, A. L. \& TROTTER, C. D. (1972). Linkage map of Escherichia coli strain K-12. Bacteriological Reviews 36, 504-524.

VoGel, H. \& BonNER, D. M. (1956). A convenient growth medium for Escherichia coli and some other microorganisms. Microbial Genetics Bulletin r3, 43-44.

WU, T. T. (1966). A model for three-point analysis of random general transductions. Genetics 54, 405-4IO.

YURA, T. \& WADA, C. (1968). Phenethyl alcohol resistance in Escherichia coli. I. Resistance of strain c600 and its relation to azide resistance. Genetics 59, 177-190. 